\section{EL DOCUMENTALISMO SOCIAL MODERNO DE DOROTHEA UNA REFLEXIÓN SOBRE LOS “SUJETOS DE LA ACCIÓN" EN EL MUNDO RURAL ESTADOUNIDENSE}

MODERN SOCIAL DOCUMENTALISM BY DOROTHEA: A REFLECTION ON THE "ACTION SUBJECTS" IN THE RURAL WORLD IN USA

María Luz Arroyo Vázquez UNED de Madrid

\section{Resumen:}

Abstract:

Durante la Gran Depresión, Dorothea Lange In the Great Depression, Dorothea Lange fue una de las más importantes fotógrafas was one of the most important documentalis documentalista de los Estados Unidos. photographer in the United States. Born in Nacida en el seno de una familia de clase a middle class family, Lange aims to reflect media, Lange pretendía reflejar la realidad the reality where USA society lived during a que vivía la sociedad estadounidense durante tragic period as the Wall Street Crash of 1929 un trágico período como fue el Crac del 29 y and to call social awareness.

así llamar a la toma de conciencia social.

Palabras claves:

\section{KEY WORD:}

Dorothea Lange, documentalism, photograph.
"La cámara es un instrumento que enseña a la gente cómo ver sin la cámara" Dorothea Langue

\section{INTRODUCCIÓN}

Dorothea Lange, fotógrafa y reportera estadounidense, fue una de las iniciadoras del documentalismo social moderno. Una de las etapas fundamentales en la carrer como fotógrafa de Lange fue la labor documental que realizó para el gobierno federal en los años 1935-1939, período en el que sus fotografías documentaron la situación en la que se hallaba el mundo rural americano. Sus imágenes reflejaron las condiciones de vida y de trabajo del ámbito rural, retratando a seres humanos con vida propia como "sujetos y no sólo objetos de la acción". Lange supo captar a través de sus imágenes del pueblo estadounidense un momento tan complejo y crítico de la historia de los Estados Unidos como fue la etapa de la Gran Depresión que tuvo lugar en los años treinta del siglo XX. En ese período, Lange ayudó al gobierno federal en su programa de recuperación y reforma económica y en su objetivo de restaurar la prosperidad y prevenir crisis venideras.

Los documentos fotográficos que Lange realizó en el medio rural reflejaron las condiciones de vida y de trabajo en ese espacio, ayudando al pueblo americano a que comprendiera la gravedad de la crisis económica, pero, al mismo tiempo, mostrándole la esperanza de poder salir del estado crítico en que se hallaba. Como señala Susan Sontag, la fotografía resultó ser muy eficaz pues ofrecía "un modo expédito de comprender algo y un medio compacto de memorizarlo" (Susan Sonntag, 2003: 31). Las imágenes que captó Lange en esa etapa fueron el resultado de una mirada crítica, reflejando una realidad que hacía pensar, sobre todo, en las circunstancias que rodeaban a las personas que retrataba tal y como ocurrió en el caso de, tal vez, su fotografía más famosa, "Migrant Mother". En el momento en el que se escriben estas líneas, en el que padecemos una importante crisis económica mundial, esa fotografía de Lange adquiere un significado simbólico muy actual por su gran capacidad de invitar al observador a la reflexión y a la empatía.

\section{LA FOtografía documental de Dorothea LANG}

La fotografía documental es aquella que se constituye en una evidencia respecto a la realidad, es testimonial y se refiere a lo que se denomina fotografía social. Según Linda Gordon, historiadora y biógrafa de Dorothea Lange, "el concepto de documental en fotografía tiene la connotación de "revelar la verdad y promover la justicia social" (Gordon 2009: xvi). 
Dorothea Lange fue una de las grandes fotografas documentales, conocida por sus imágenes del éxodo de los trabajadores del campo durante la Gran Depresión. Lange desarrolló su carrera fotográfica en los años treinta del siglo XX, un período histórico que, sin duda, se convirtió en lo que sería la mayor influencia en su fotografía. En esa etapa, Lange se convirtió en un claro exponente del documentalismo social fotográfico, documentando los espacios, las condiciones y el medio en el que se desenvolvió el pueblo americano, y reflejándolo tanto de forma tanto individual como colectiva. La historiadora estadounidense Linda Gordon afirma que, a pesar de los problemas de la Depresión, ésta "creó un momento de idealismo, imaginación y de unidad en la esperanza americana" en el que "ningún fotógrafo de su tiempo, quizás ningún artista hiciera más que Lange para avanzar en esta visión democrática, pues "sus fotografías ampliaron la compresión popular de quienes eran los americanos, ofreciendo una representación más visual de la nación" (2009: xiv)

Lange fue una firme defensora de la fotografía directa, objetiva y sin que pasara por ningún tipo de manipulación. Sus imágenes trataban de invitar a la reflexión, a mostrar al hombre y sus circunstancias sin la manipulación de las situaciones. No obstante, algunas veces se advierte que sus fotografías de documentalismo social son posadas, y el sujeto advirtiera y fuera consciente de la cámara, pero eso no se trata de una actuación sino, simplemente, de un mostrarse en forma estática. Lange no solía preparar a los sujetos de la acción, pero si lo hacía a propósito, les hacía mirar directamente a la cámara. Como fotógrafa documental, Lange fotografiaba a la gente en su ambiente, como eran, y trataba de encuadrar y captar lo que las personas y el ambiente tuvieran que ofrecer en un sentido que pudiera evocar un significado; les fotografiaba en el contexto de sus vidas (George Elliot 1966: 7). A veces, Lange se acercaba al sujeto, pero decidía excluir el entorno, es decir, se centraba en la humanidad del sujeto de la acción. Otras veces, incluía el fondo pues si le interesara éste.

Esta fotógrafa norteamericana generó una conciencia social a través de la mirada de su cámara. Se advierte, por un lado, que en sus imágenes existía un cierto carácter de denuncia, con el fin de producir una transformación social y, asimismo, parecían tener también como finalidad la comprensión de la humanidad. Según Linda Gordon, la mayoría de las fotografías de Lange eran optimistas e incluso utópicas, no a pesar de, sino precisamente por sus frecuentes descripciones de la tristeza y de las privaciones. Al mostrar a los sujetos en una situación triste, destacaba que no eran merecedores de las privaciones que padecían y llamaba la atención sobre el hecho de que la democracia no se había logrado de una forma plena, al mismo tiempo, que afirmaba que una democracia mejor era posible (2009: xiv)

El MARCo histórico
En 1929, el Crac de la bolsa de Nueva York puso de manifiesto los problemas de base de la economía americana, e inició una larga Depresión de alcance mundial. De este modo, al comenzar la década de los años treinta, los Estados Unidos se encontraban sumidos en una profunda crisis económica, que se extendió al resto del mundo occidental, como ha ocurrido en el momento en el que se escriben estas líneas. Las potencias europeas como Gran Bretaña y Francia estaban endeudadas con Estados Unidos y a su vez exigen el pago de las reparaciones de guerra a Alemania. Este sistema triangular hacía que la Depresión, en principio norteamericana, se extendiera a Europa y llegase a ser considerada un fenómeno mundial. De ahí que Europa intentase resolver el problema de las deudas en una búsqueda de lograr estabilidad económica. En los tres años que precedieron la llegada de Roosevelt al poder, Estados Unidos dejaron de ser el ejemplo de "tierra prometida". Todo lo invadieron el caos y el desaliento. A la gente le entró el pánico y retiró su dinero de los bancos, lo cual empeoró la situación.

Estados Unidos, al igual que el resto del mundo atlántico, vivían una profunda depresión en el momento de ser elegido presidente el candidato demócrata Franklin Delano Roosevelt en 1932. Roosevelt ofreció al país un New Deal con el que el gobierno intervendría para estabilizar la economía y restablecer el bienestar. El día 4 marzo de 1933, Roosevelt tomó posesión de su cargo en los Estados Unidos y el día 5 lo hizo Hitler en Alemania. Estos políticos representaban dos enfoques muy diferentes para afrontar la crisis: la democracia y el totalitarismo fascista. Sin embargo, la sensación de desesperanza cambió cuando Roosevelt ocupó la presidencia, proyectando confianza y optimismo e impulsando la unidad nacional. Así, la década de los años treinta, de estancamiento y colapso en la economía también se caracterizó por convertirse en un período de cohesión y unidad (Galbraith 1975: 236). Estados Unidos proyectaron una imagen de país en guerra psicológica contra la Depresión mundial. No obstante, Roosevelt en 1933, aunque está atento a cuestiones de política internacional, su atención quedó canalizada hacia los problemas domésticos, porque estaba convencido de que el problema principal era la Depresión "en casa"..

En ese contexto crítico empezó a funcionar el New Deal, el mundo occidental permaneció atento en todo momento al desarrollo de una política nueva, democrática y distinta de la llevada a cabo por los regímenes fascistas y totalitarios. El New Deal fue todo un símbolo, una idea potente, una política nueva de ámbito nacional, pero con proyección internacional. Al mismo tiempo, fue un programa político controvertido que cuenta con detractores y admiradores. A partir de una situación de urgencia surgió un gran número de medidas legislativas para hacer frente a la Depresión.

Uno de los organismos que se fundaron durante el New Deal fue el Farm Security Administration (F.S.A.) (departamento para la seguridad agraria), que se creó dentro 
del departamento de agricultura en 1937, pero sus raíces estaban en el Resettlement Administration (R.A.) (departamento para la reubicación) que había sido creado en 1935. Su finalidad era documentar la situación difícil que atravesaron los campesinos durante la Gran Depresión y el Dust Bowl. Alrededor de seis mil emigrantes provenientes de Medio Oeste llegaban a California cada mes, arrastrados por la falta de empleo, la sequía y la pérdida del arriendo de las granjas en las que trabajaban. Roy Stryker fue el jefe de una sección fotográfica en la R.A. y, más tarde, el Farm Security Administration (F.S.A.), desde 1935 hasta 1942. Durante su existencia, el RA/FSA creó 77.000 fotografías documentales en blanco y Negro y 644 en color. En 1942, el FSA se trasladó a la Office of War Information (la oficina de información de la guerra).

\section{VIDA Y TRAYECTORIA PROFESIONAL}

Dorothea Margarette Nutzhorn nació en Hoboken, Nueva Jersey (Estados Unidos), el 25 de mayo de 1895, en el seno de una familia de clase media. Sus padres, Joan y Henry Nutzhorn, eran la segunda generación de una familia de origen germanoamericano. Hubo dos situaciones traumáticas en su vida. A la edad de 7 años, padeció la poliomielitis, que le dañó la pierna derecha, un hecho que le causará un trauma y le marcará para toda la vida. De hecho, llevó faldas largas en la edad adulta para esconder su cojera. El segundo trauma se lo produjo la separación de los padres. Como dato curioso, decidió quitarse su segundo nombre (Margarette) y adoptó el apellido de soltera de su madre, Lange cuando se marchó a vivir por su cuenta, pues se sentía avergonzada de haber sido abandonada por su padre.

Aunque Dorothea vivía en Hoboken, todos los días iba con su madre en ferry a la ciudad de Nueva York, donde su madre trabajaba en una biblioteca pública mientras que ella iba a la escuela. No fue a la universidad y decidió estudiar fotografía, a pesar del deseo de su madre de que se dedicara a la enseñanza. En 1917, estudió fotografía en la Clarence White School, Columbia, Nueva York, y participó como aprendiza en numerosos estudios fotográficos. En 1918, se dedicó a viajar por el mundo con una buena amiga, y terminó por establecerse en San Francisco, donde abrió un estudio fotográfico y trabajó como retratista durante más de una década. Esta fue una etapa en la cosechó sus primeros éxitos. En 1920, se enamoró y casó con su primer marido, el pintor Maynard Dixon, con quien estuvo casada durante quince años y con el cual tuvo dos hijos. Dixon era un pintor de paisajes y retratos, ejerciendo una cierta influencia en ella. Los problemas surgieron en la pareja, pues su marido pasaba varias semanas e incluso meses fuera de casa, realizando exposiciones y manteniendo relaciones extra-conyugales, mientras que ella tenía que hacerse cargo de la casa y los hijos y compaginarlo con su propio trabajo de fotógrafa. Hacía retratos a gente pudiente para obtener una fuente de ingresos con la que poder mantener a su familia.

Con el comienzo de la Gran Depresión, se interesó por los temas sociales y esto le llevó a cambiar su trabajo centrado en realizar retratos en el estudio por fotografiar en la calle, captando con su lente a desempleados y gente sin hogar. Esta labor atrajo la atención de fotógrafos locales y la llevó a ser contratada por el gobierno federal. Fue entonces cuando al ir de su estudio hizo su primera fotografía documental al fotografiar una de las largas colas que hacía la población para esperar recibir un poco de alimento. El reparto de alimentos de la imagen quecaptó pues estaba dirigido por una mujer acomodada, llamada Lois Jordan, conocida como el White Angel (el ángel blanco) por lo que fue titulada "White Angel Bread Line".

Lange realizó esta primera fotografía documental en San Francisco, circa 1933, y, sin duda, fue una de las más importantes de su carrera. En la fotografía, destaca un hombre con sombrero, inclinado hacia delante y apoyado en una barandilla, entre una multitud de gente que también lleva sombrero pero que está de espalda. No se aprecian los ojos del hombre, sólo la mandíbula. Su postura nos hace pensar en una persona a la que no le queda más remedio que estar en una de esas largas colas. Esta imagen nos hace reflexionar sobre la situación de crisis económica y social que se vivía en América tras el Crac de 1929. En 1934, Lange presentó su primera exposición en la galería de Willard Van Dike. Entre los asistentes estaba Paul S. Taylor, profesor de economía de la Universidad de California, que estaba estudiando los efectos sociales de la Gran Depresión. Taylor era conocido por sus estudios sobre la pobreza en el mundo rural y las migraciones de los campesinos, así que pensó que las fotografías de Lange podrían complementar sus informes sobre el tema.

Poco tiempo después, en 1935, Lange trasladó su lugar de residencia a Berkeley, California, tras casarse con Paul S. Taylor. El matrimonio fue sólido y fructífero en lo personal y en el terreno profesional. Taylor formó a Lange en asuntos sociales y económicos, y juntos documentaron la pobreza en el medio rural y la explotación de los cultivadores y de los trabajadores inmigrantes. Taylor hacía las entrevistas y recogía la información económica, y Lange tomaba las fotos. Lange permaneció junto a Taylor el resto de su vida, durante treinta años, hasta que ella falleció. Su segundo marido la admiraba y la consideraba un genio, siendo un gran apoyo para su carrera y una gran influencia en su trabajo. La relación que mantuvieron les enriqueció mutuamente pues mientras que "él la enseñó sobre los problemas sociales que ella estaba fotografiando, ella le enseñó a ver" (Gordon 2009: xvi). Asimismo, ambos apoyaron las actividades huelguísticas convocadas por los sindicatos, el establecimiento de cooperativas y el fin de las prácticas discriminatorias a los inmigrantes. En 1935, Lange y Taylor documentaron la situación de los granjeros que 
habían emigrado a Nipomo y al Imperial Valley para la California State Emergency Relief Administration (departamento para la ayuda urgente en el estado de California). Cuando le llegó a Roy Stryker, economista, fotógrafo y miembro del gobierno, una copia de los informes que Lange y Taylor habían elaborado, éste le ofreció a Lange un trabajo en el Resettlement Administration (R.A.) (departamento de reubicación) que se había creado en agosto de 1935. No obstante, Lange no se trasladó a vivir a Washington, como hacían la mayoría de los que trabajaban para el citado organismo, sino que permaneció en California. Lange empezó a reflejar ese entorno rural mediante documentos fotográficos de las condiciones laborales de la época, dedicando especial interés en captar a los más afectados por la Gran Depresión norteamericana de los años 30

Así, a partir del año 1935 empezó a colaborar con el gobierno de Franklin Delano Roosevelt y su programa de recuperación y reforma económica, el New Deal, trabajando para elorganismofederal denominado ResettlementAdministration(R.A.),(departamento de reubicación), creado en 1935, y, posteriormente, para el organismo que le sustituyó en 1936, el Farm Security Administration (F.S.A) (departamento para la seguridad agraria), cuya sección fotográfica constituyó un impresionante archivo gráfico que abarcaba todos los aspectos de la vida rural americana y ayudó a comprender al pueblo americano la gravedad de la crisis económica por la que atravesaba en ese período. A principios de 1937, después de haber trabajado en Nipomo, California, en el año 1936, Lange regresó al Imperial Valley para documentar el estado crítico en que se hallaba. Había una afluencia masiva de miles de personas sin hogar que no dejaban de llegar y cuando por fin se establecían allí muchos se encontraban con la triste realidad de que no había trabajo para ellos.

Milton Meltzer, en la biografía que escribe sobre Lange, describió el viaje documental que Lange realizó en ese año y las vicisitudes económicas por las que atravesó el proyecto documental. Debido a la escasez de fondos para financiarlo, se había interrumpido durante unos meses, en los últimos meses del año 1936. A finales de enero de 1937, Roy Stryker, el jefe de la sección fotográfica del Farm Security Administration (F.S.A) (departamento para la seguridad agraria), pudo volver a contratar a Lange que comenzó a trabajar en el Imperial Valley, después de que hubiera aprobado su viaje a esa zona. Lange trabajó con su amiga Ron Partridge, tratando de fotografiar a la gente sin que posara para ello (Meltzer 1978: 163-70). Las fotografías que tomó ese año 1937, no sólo documentaron a los Okies y a los Arkies, sino también a los trabajadores mejicanos, a los recolectores de lechuga Filipinos y una granja japonesa.

También, a finales de la década de los años treinta, concretamente entre 1938 y 1939, Lange preparó junto a su marido, Paul S. Taylor, el libro An American Exodus, A Record of Human Erosion, que fue editado en 1939. La obra sería el fruto de la estrecha colaboración entre la fotógrafa y el científico social. En el citado libro se narra el trágico éxodo de miles de americanos de una tierra que se había quedado empobrecida. Lange y Taylor realizaron una gran labor documental en la que aparecían los textos que recogían un análisis del fenómeno migratorio junto a las fotografías, analizando el fenómeno de la migración motivada por la Depresión. En el microfilm se recogían fragmentos de conversaciones escuchadas en el momento en que se tomaron las fotografías y se describía la situación desesperante que padecían. Estos emigrantes competían con los trabajadores mejicanos y con otros emigrantes, pero no se les ofrecía una tierra para trabajar, sino trabajar en la tierra (Lange y Taylor 1999). La tenencia de la tierra estaba en muy pocas manos. Así, en 1935, en el Imperial Valley tan sólo setenta y cuatro individuos controlaban la mayor parte de la tierra cultivable (Federal Writer's Project 1939: 639-40).

El trabajo de Lange entre los años 1935 y 1939 resultó ser especialmente reconocido, alabándose las imágenes que documentaban las consecuencias de la Gran Depresión. Entre las fotografías más conocidas de Lange de este período podemos destacar las siguientes; "Migrant Mother" Febrero 1936, "Arkansas mother" Noviembre 1938, "Eighty-year old grandmother" Noviembre 1936, "FSA Rehabilitation Clients" Agosto 1939 y , "Japanese mother and daughter" Marzo 1937. En 1941, Dorothea fue galardonada con una beca Guggenheim, que dejó tras el ataque de Pearl Harbor, pues quiso registrar la evacuación forzosa de los japoneses americanos (Nisei) y su reubicación en los campos de concentración del occidente del país. Entre 1942 y 1944 Lange fotografió los campos de internamiento de los americanos de origen japonés, pero fue censurada por parte de Autoridad de Reubicación de la Guerra.

Langecubriótodoslosactosdereubicacióndelosjaponeses, suevacuacióntemporalylos primeroscampos permanentes.Paramuchosobservadores, susfotografías demuchachas japonesas estadounidenses presentando honores a la bandera antes de ser enviadas a campos de concentración es un recuerdo de las políticas de detención de personas sin ningún cargo criminal y sin derecho a defenderse. Sus imágenes fueron tan obviamente críticas que el Ejército las embargó. Dichas fotografías están disponibles en la actualidad en la División Fotográfica y la Biblioteca Bancroft de la Universidad de California. Después de la Segunda Guerra Mundial, Dorothea Lange comenzó con problemas de salud y estuvo inactiva desde 1945 hasta 1951. En la década de los 50, mientras su estado de salud se lo permitió, realizó diversos trabajos en Europa, América Latina, Asia y África, así como un estudio sobre el sistema judicial californiano.

A partir de 1964, tras tener conocimiento de que padecía un cáncer de esófago, se consagró a sus dos últimos proyectos: organizar una retrospectiva de su obra en el Museum of Modern Art (MOMA) y a documentar su vida. El 11 de octubre de 1965 falleció en San Francisco. La obra fotográfica de Lange puede ser vista en el 
departamento de arte del museo Oakland de California que posee la mayor colección de sus fotografías, que son consideradas como una parte trascendental de la historia de Estados Unidos.

\section{LA LABOR DOCUMENTAL DE LANGE EN EL MUNDO RURAL}

Como hemos mencionado anteriormente, las obras más conocidas de Lange que tienen como marco el mundo rural las tomó en los años 30 del siglo XX, es decir, durante la época de la Gran Depresión, en la que una profunda crisis asoló el país y miles de campesinos no tuvieron mas remedio que abandonar sus casas en la búsqueda de un destino mejor. En los años 1935-1939, Lange puso el énfasis en captar a la gente que trabajaba en el ámbito rural, mostrando respeto por su trabajo y reflejando los efectos adversos de la Gran Depresión, del Dust Bowl, y del aumento de la mecanización. Sus fotografías retrataron a la gente que se desplazó desde las granjas del Medio Oeste y que emigró hacia el Oeste o hacia las ciudades industriales en la búsqueda de trabajo.

A mediados de los años treinta, en plena Gran Depresión, el Medio Oeste de los Estados Unidos fue asolado por una gran sequía, denominada Dust Bowl. Las grandes tormentas de polvo terminaron de destruir las cosechas que aún no habían sucumbido. Muchos granjeros, que habían hipotecado sus granjas, perdieron sus tierras, malvendieron entonces sus posesiones y un gran número de ellos puso rumbo a California. Esperaban encontrar allí trabajo como temporeros en las grandes explotaciones agrícolas. Fue entonces cuando el departamento para la seguridad agraria, el Farm Security Administration (F.S.A.), investigaba las condiciones de vida de las familias que eran contratadas para trabajar en los campos de algodón en Arizona y California.

California siempre había necesitado a estos braceros para recoger las cosechas. Primero habían llegado chinos y japoneses; luego fueron los mejicanos, y más tarde, los filipinos. En 1936, los campesinos que llegaban para recoger la cosecha eran blancos y norteamericanos. Además, llegaban con sus familias buscando un trabajo y una nueva vida, y sin un lugar al que regresar. Además, es necesario puntualizar que, a pesar de que los jornaleros eran necesarios para la recolección de la cosecha, no gozaban de una gran estima.

Dorothea radiografió y denunció la realidad en su documento fotográfico. La descripción de las condiciones en las que llegaban los jornaleros a California, la desconfianza que generaban, la explotación laboral a la que eran sometidos o el rechazo al que se veían sometidos. Con una mirada concisa y digna, Dorothea Lange recorrió el país trabajando para los organismos oficiales Ressetlement Administration (R.A.) y Farm Security Administration (F.S.A.), que ya hemos mencionado anteriormente, con el fin de documentar la precaria situación en la que vivían los aparceros y el éxodo de los campesinos. Se convirtió así en testigo de esta época, poniendo en sus fotos al pobre y al marginal, especialmente, a campesinos, afamilias desplazadas e inmigrantes, pero, al mismo tiempo, reflejando unos sujetos a los que se acercaba de manera respetuosa, trasmitiendo una imagen humana y digna.

Su obra fue un testimonio sobre las terribles consecuencias de la Gran Depresión, testimonio por otro lado lleno de compromiso, convencida de que sus imágenes podían ayudar a cambiar las cosas. Su mirada huía de la sensiblería y de la dramatización surgiendo de un profundo sentimiento humano y de una gran conciencia social. Lange comprendió la amplitud del drama social durante la Gran Depresión, pero, al mismo tiempo, supo mantener una distancia. Con su cámara se centró en los rostros de la Depresión e hizo fotografías en las que combinaba la crítica social, el documental y la estética, tratando de acercar las duras condiciones de vida y la pobreza de la población rural a un público ignorante de la situación por la que atravesaba el país.

Las fotografías de Lange transmitían un modo de sentir, no quedándose tan sólo en la descripción de circunstancias o actividades. Las fotografías ofrecían el estudio de un sujeto en el que la artista recogía y transmitía su mirada, su gesto, su postura de un sujeto anónimo que hacía ir al observador a ir de lo particular a lo general. Así, se trata de reflejar a un recolector en la indigencia o a un campesino en paro. A veces, sus imágenes captaron pequeños instantes de la vida cotidiana en el campo, momentos aparentemente banales pero que tenían con un gran sentido metafórico sobre las condiciones sociolaborales del entorno y de su tiempo. Un aspecto fundamental de las fotografías documentales de Dorothea Lange fue la finalidad propagandística y publicitaria por parte de las agencias para las que trabajaba, pues trataban de apoyar el establecimiento de campos de emigrantes en el medio rural por el departamento de reubicación, the Resettlement Administration (R.A.).

Asimismo, a Lange le preocupada e interesaba la difusión de sus fotografías y, por ello, además de ver la necesidad de que estas llegaran a los organismos para los que trabajaba, también quiso que sus fotografías aparecieran en la prensa, en distintos organismos oficiales o incluso en el libro que preparó junto a su marido. Así, entre 1937 y 1940, a título de ejemplo, sus imágenes fueron utilizadas en un informe para el Senado estadounidense, en 1939 en el libro que publicó con Paul S. Taylor An American Exodus. A Record of Human Erosion, en una exposición sobre el Works Progress Administration (W.P.A.) (departamento para el desarrollo de obras sociales) en San Francisco, y en un gran número de periódicos y revistas.

\section{“MigRANT MOTHER” O EL ICONO DE LA GRAN DEPRESIÓN}

Las imágenes de los aparceros de Lange se han convertido en verdaderos iconos de los años 30 en los Estados Unidos. Uno de los documentos gráficos más significativos 
fue, sin duda, la llamada "Migrant Mother" en la que Dorothea Lange reprodujo la imagen de lo que significó la Gran Depresión, quedando como un icono de esa época. La mujer en la foto era Florence Owens Thompson, pero Lange aparentemente nunca supo su nombre. En 1960, Lange habló de su experiencia al tomar la foto:

\section{Vi y me acerqué a la famélica y desesperada madre y me acerqué a ella como si me sintiera atraída por un imán. No recuerdo cómo le expliqué mi presencia o la de mi cámara, pero recuerdo que ella no me hizo preguntas. Hice seis exposiciones, trabajando cada vez más cerca en la misma dirección. No le pregunté por su nombre ni por su historia. Ella me dijo su edad, tenía 32 años. Me dijo que hor súa nombre ni por su historia. Ella me dijo su edad, tenía 32 años. Me dijo que habian estado viviendo de verdura congelada de los campos de los alrededores y de los pájaros que los niños mataban. Acababa de vender los neumáticos de su coche para comprar alimentos. Se sentó en aquel cobertizo de la tienda con sus niños abrazados a ella, y parecía saber que mi fotografía podría ayudarle, y entonces me ayudó a mí. Había una cierta igualdad en esto.}

La identidad de Florence Owens Thompson no se conoció hasta finales de la década de los años setenta. Florence Owens nació el 1 de septiembre de 1903, en Oklahoma. Se casó cuando tenía 17 años con Cleo Owens con quien tuvo seis hijos. Al morir su marido de tuberculosis, tuvo otro hijo de otra relación. Después se casó con James R. Hill, con quien tuvo otros cuatro hijos. Después de la Segunda Guerra mundial se casó con George Thompson. Durante una gran parte de su vida, Florence Owens sufrió penuria y privaciones. Cuando contrajo la enfermedad de cáncer, uno de sus hijos, Troy Owens, pidió ayuda para costear el tratamiento y, de una forma generosa el público se volcó en ayudarla, pues logró recaudar 35.000 dólares. Florence no se recuperó y murió el 16 de septiembre de 1983, unas semanas después de cumplir los 80 años. Fue enterrada en un cementerio en Empire, California y en su lápida se puede leer: "Migrant Mother: A Legend of the Strength of American Motherhood ("Madre Migrante: una legenda de fortaleza de la maternidad americana").

La fotografía "Migrant Mother es universalmente conocida y, en ella realmente se nos habla del sujeto de la acción, de una madre recolectora de guisantes en la indigencia, y no de la persona que la realizó. Esta fotografía destacó por su mirada singular y por su estilo documental, centrado en la vida rural. El día en el que Lange tomó esa fotografía ha sido ampliamente descrito. Iba de camino a casa después de haber realizado un trabajo documental sobre las condiciones de vida y laborales de los trabajadores del campo que habían emigrado a California. Estaba cansada y cuando le quedaban 7 horas de conducción para llegar a su casa, pasó por un cartel que ponía Campo de recolectores de guisantes. Sabía que la última helada había arruinado el cultivo de guisantes, y decidió visitar el campo y documentar la situación en la que se pudiera hallaba la gente allí. Vio a la mujer que sería el sujeto de su fotografía Migrant Mother. Realizó seis fotos y la última se convertiría en "el símbolo eterno y universal del sufrimiento en la cara de la adversidad" (Curtis 1989: 47).

Lange se apresuró a revelar las fotografías y presentarlas al F.S.A. y al San Francisco News, ya que pensaba y no estaba descaminada que esas fotografía podrían ayudar a atraer la atención sobre la situación difícil de los granjeros emigrantes americanos. Igualmente, tenía razón al pensar que la historia se publicaría en los diarios de todo el país, ya que el gobierno federal se apresuró a enviar comida a los campos en los que la gente se hallaba en la indigencia. Normalmente, Dorothea Lange solía tomar notas biográficas de los sujetos a los que fotografiaba, sin embargo, en esa ocasión, mencionó muy pocos datos, ni siquiera anotó el nombre y mucho de lo que escribió era inexacto, como llegaron a desvelar Florence Owens, la protagonista de esta historia, y sus hijos (Dunne, 2002). Aunque el gobierno envió comida a Nipomo, la familia de Florence Owens ya estaba de camino hacia Watsonville. La familia se quejó de que la fotografía fuera publicada pues decía que Lange había prometido no hacerlo y pensaba que se había beneficiado económicamente de ello y sentía que debería haber recibido algo. Aunque Lange no recibió dinero directamente por ello pues hizo la fotografía para el organismo que trabajaba, el F.S.A., indudablemente, la fotografía impulsó su carrera.

La selección que Lange hizo para captar la escena es muy reveladora. La hija adolescente de Florence Owens quedó excluida a propósito de la fotografía. Aparecía en las dos primeras instantáneas de la serie, pero Lange pensó que si la incluía haría que el espectador especulase sobre la edad que había tenido la madre cuando empezó a tener hijos (Curtis 1989: 55). Al mismo tiempo, la familia ideal no tenía más de tres hijos y, por ello, poner a siete hijos podría haber distraído y haber causado que la gente tuviera una actitud menos favorable hacia ella (Curtis 1989: 52).

En la tercera foto, sólo se ve la madre amamantando al más pequeño de sus hijos. En la cuarta foto, Lange añadió a uno de sus hijos, que descansó su mentón en el hombro de su madre (Curtis 1989: 58). La quinta fotografía era idéntica, pero tomada desde otro ángulo. En la sexta, que era la última foto, Lange puso a otro niño, pero dos de los niños no miraban a la cámara así que Lange pidió a la madre que pusiera la mano derecha en su rostro, y esto produjo el efecto que ella quería (Curtis 1989: 65). Ello suavizó la ansiedad de la madre ante la cámara y trasmitió la idea de preocupación por el bienestar de su familia. La madre estaba preocupada por si dejaba resbalar a su hijo dormido, así que en la foto original se puede ver como aprieta el pulgar, lo cual no fue detectado por Lange, que, al advertirlo más tarde, alteró ese detalle del negativo original (Curtis 1989: 67).

A MOdo de CONCLusión 
Dorothea Lange merece ocupar un lugar destacado en la historia de la fotografía documental, pues sus imágenes consiguen comunicar con el espectador de una forma intensa y clara en su afán de contarnos la realidad social.

La cámara de Lange en los años de la Gran Depresión registró la situación en la que vivían los sujetos de la acción del mundo rural de una forma directa, en imágenes concisas, contundentes y sobrias. Sus fotografías mostraban la originalidad de su percepción, que, a través de la representación del ciudadano anónimo y corriente, de los casos particulares, conseguía hacer reflexionar al público que las observaba sobre el universo colectivo. Con su lente, Lange creó valiosas imágenes por las que América se pudo reconocer a sí misma. Por ello, muchas de sus obras que reflejaban un minucioso análisis de la realidad han trascendido y se han convertido en verdaderos iconos que han logrado sacudir la conciencia no sólo del pueblo americano sino de la humanidad.

En definitiva, Lange, "la fotógrafa del pueblo", como ponía en su tarjeta de visita, es la fotógrafa americana más renombrada del siglo XX por su testimonio gráfico de los efectos de la Gran Depresión que sufrió el pueblo norteamericano y por ser una de las grandes pioneras del documentalismo social moderno.

\section{REFERENCIAS BIBLIOGRÁFICAS}

Coles, R. et al., Dorothea Lange: Photographs of a Lifetime, New York, Aperture Monograph, 1996 ----, Doing Documentary Work, New York and Oxford, The New York Public Library and Oxford University Press, 1997.

Curtis, J., Mind's Eye, Mind's Truth: FSA Photography Reconsidered, Philadelphia, Temple University Press, 1989.

Dunn, G., "Photographic License," in New Times Magazine. http://www.newtimes-slo.com/ archives/cov_stories_2002/cov_01172002.html. Acceso: 30 de Julio de 2010.

Gordon L., Dorothea Langue. A Life Beyond Limits, London, New York, W.W. Norton and Company, 2009.

Gordon, L. and Okihiro, G. Y., eds., Impounded: Dorothea Lange and the Censored Images of Japanese American Internment, New York, W. W. Norton and Company, 2006

Federal Writer's Project, California, A Guide to the Golden State, New York, Hastings House, 1939.

Fourmont, G., "La fotógrafa que ilustró la dignidad de los más pobres", Público, 9 de junio de 2010, p. 41.

Galbraith, J. K., El Crac del 29. Barcelona, Ariel, 1975.

Hunt, J. G. (ed.)., The Essential F.D.R, New York, Gramercy Books, 1995,
Khasnis, G., "Two women and a photograph", The Hindu, Online edition of India's National Newspaper. Sunday, April 30, 2006. Acceso 20 de septiembre de 2010.

Lane, J. and O'Sullivan, M. (eds.), A Twentieth-Century American Reader, Vol.1 1900-1945. Washington D.C., United States Information Agency, 1999.

Lange, D. and Taylor P., An American Exodus. A Record of Human Erosion, facsimile of the original edition, Sam Stourdzé (ed.), Paris, Edition Jean Michel Place, 1999.

Library of Congress, "American Memory. American from the Great Depression to World War II (Black and White Photographs from the FSA-OWI 1935-1945)". 15 de septiembre de 2010. http://rs6.loc.gov/ammem/fsahtml/fahome.html. This site has pertinent information.

Library of Congress, “American Memory. Voices from the Dust Bowl: The Charles L. Todd and Robert Sonkin Migrant Workers Collection 1940-1941". 15 de septiembre de 2010. http:// rs6.loc.gov/ammem/afctshtml/tshome.html.

Meltzer. M., Dorothea Lange: A Photographer's Life, New York, Farrar Straus Giroux, 1978.

Museum of Modern Art, Dorothea Lange, New York Doubleday \& Co., 1966. (Introducción por George P. Elliot)

Ohrn, K. B., Dorothea Lange and the Documentary Tradition, Baton Rouge, Louisiana State University Press, 1980

Oakland Museum of California. Art Department, Dorothea Lange Collection. http://www. museumca.org/global/art/collections_dorothea_lange.html.

Partridge, E., Restless Spirit: The Life and Works of Dorothea Lange, New York, Viking Press, 1998.

Perchick, M., "Dorothea Lange; 'the greatest documentary photographer in the United States." PSA Journal. 6/1/1995. http://www.highbeam.com/library/docFree. asp?DOCID=1G1:17181090. 1 de septiembre de 2010.

Sontag, S., Ante el dolor de los demás, Madrid, Santillana Ediciones Generales S.L., 2003.

Spirn, A., W., Daring to Look: Dorothea Lange's Photographs and Reports from the Field, Chicago, University of Chicago Press, 2008.

Stott, W., Documentary Expression and Thirties America, New York, Oxford University Press, 1973.

Stourdze, S. (ed.), Dorothea Lange, The Human Face, Paris, NBC Editions, 1998. 